\title{
INSTRUMENTAÇÃO TÉRMICA APLICADA AO PROCESSO DE PRODUÇÃO DE CARVÃO VEGETAL EM FORNOS DE ALVENARIA ${ }^{1}$
}

Solidônio Rodrigues de Carvalho ${ }^{2}$, Valério Luiz Borges ${ }^{2}$, Bruno Henrique Oliveira Mulina ${ }^{3}$, Rogério Lima Mota de Oliveira ${ }^{3}$, Edson Alves Figueira Júnior ${ }^{3}$ e José Silvio Pessoa Filho ${ }^{3}$

\begin{abstract}
RESUMO - Neste estudo, propôs-se avaliar a instrumentação térmica de fornos retangulares destinados à produção de carvão vegetal, denominados RAC220, com capacidade individual para produzir 30 toneladas de carvão por ciclo de carbonização. Os objetivos foram medir as temperaturas em pontos estratégicos do forno e identificar as relações entre temperatura e produção de carvão vegetal. Nesse sentido, este trabalho consistiu em instalar 22 sensores tipo PT100 por forno. Por meio de um sistema eletrônico supervisório conectado a uma rede sem fio, as temperaturas foram armazenadas e, via software com interface gráfica, visualizadas na forma de gráficos e tabelas. Ressalta-se que a concepção, desenvolvimento e montagem de todos os equipamentos eletrônicos foram de responsabilidade da Faculdade de Engenharia Mecânica da Universidade Federal de Uberlândia. O sistema atualmente está em fase de testes e permite analisar e comparar os históricos de ciclos de produção, bem como realizar interferências para corrigir os ciclos de carbonização em tempo real de produção. Tais informações guiam e auxiliam o carbonizador durante todos os estágios da produção de carvão vegetal. Por meio dos resultados, verificou-se que a instrumentação térmica de fornos destinados à produção de carvão vegetal permite, entre diversos fatores, reduzir o tempo de pirólise e resfriamento e minimizar as perdas e falhas de produção, além de aumentar a eficiência térmica dos fornos.
\end{abstract}

Palavras-chave: Instrumentação, Carvão vegetal e Temperatura.

\section{THERMAL INSTRUMENTATION APPLIED TO CHARCOAL PRODUCTION}

\begin{abstract}
This work proposes the thermal analysis of rectangular brick kilns which has an individual capacity to produce 30 tons of charcoal for carbonization cycle. The objective of this work was to measure the temperature from thermocouples located in different sites in the kilns and to establish a relationship between temperature and charcoal production. In this sense, the thermal instrumentation predicted the installation of 22 PT100 thermocouples in each kiln. These sensors were connected to a mother boarder that emits the signal to a computer by an electronic circuit and a wireless net. The temperatures were stored in a supervisory system which presented the measured data in form of graphs and tables. Such information can be used to guide and to assist the carbonizing agent during the whole stages of the charcoal production. This measurement procedure with a statistical analysis represents an important tool to reduce the time of drying, pyrolysis and cooling. It can also minimize the losses and increase the thermal efficiency of the production process.
\end{abstract}

Keywords: Instrumentation, Charcoal and Temperature.

\footnotetext{
${ }^{1}$ Recebido em 13.05.2011 e aceito para publicação em 28.05.2012.

${ }^{2}$ Universidade Federal de Uberlândia / Faculdade de Engenharia Mecânica. E-mail: <srcarvalho@mecanica.ufu.br>e <vlborges@mecanica.ufu.br>.

${ }^{3}$ Programa de Pós-Graduação em Engenharia Mecânica pela Universidade Federal de Uberlândia. E-mail: <brunomulina@ gmail.com>, $<$ rogerio@mecanica.ufu.br>, <edson@mec.ufu.br>e < jspessoa_88@ hotmail.com>.
} 


\section{INTRODUÇÃO}

O desenvolvimento de tecnologias para controlar termicamente fornos industriais é fundamental para aumentar a produtividade e o lucro, além de gerar produtos de maior qualidade. Especificamente em fornos de produção de carvão vegetal, a previsão do tempo de secagem da madeira, do tempo de produção e da homogeneidade da carbonização é fundamental e de difícil execução prática. Normalmente, variáveis importantes que interferem diretamente na qualidade do produto final, como o tempo de abertura e fechamento das chaminés, umidade da madeira, tempo de pirólise e resfriamento do carvão, são fortemente dependentes da experiência prática dos carbonizadores (técnico responsável pela carbonização).

Nesse sentido, este trabalho propôs-se a instrumentação térmica de fornos de alvenaria, denominados RAC220. O sistema eletrônico de monitoramento tem como objetivo contribuir para minimizar as perdas e aumentar a eficiência térmica dos ciclos, a partir da análise dos campos térmicos desenvolvidos no interior dos fornos.

A instrumentação térmica do processo de produção permite monitorar em tempo real a temperatura no interior dos fornos, o que contribui para a homogeneização do processo de carbonização da madeira. Consequentemente, proporciona aumento na produtividade dos fornos e da qualidade do produto final, além de contribuir para minimizar as emissões de gases de efeito-estufa.

Por meio de 22 sensores tipo PT100, instalados em cada forno e conectados a uma placa-mãe, os dados de temperatura são enviados a um computador, por um circuito eletrônico e uma rede sem fios. As temperaturas serão armazenadas em disco rígido e memórias por meio de hardwares e softwares, construídos especificamente para os fornos. Essas podem ser visualizadas na forma de mapas térmicos, gráficos e tabelas. O sistema permite ainda que usuários cadastrados possam analisar e acompanhar os ciclos de produção via internet. Como objetivo maior, pretendeu-se que no futuro o sistema de monitoramente térmico possa controlar o forno, orientando e auxiliando o carbonizador durante todas as fases de produção de carvão vegetal.

Alguns pesquisadores têm utilizado metodologias semelhantes para avaliar ciclos de carbonização. Raad e Winter (2007) apresentaram alguns procedimentos experimentais para otimizar a produção de carvão vegetal. O processo de carbonização é controlado através da medição da temperatura no interior do forno e controle do fluxo de gases. Esses autores propuseram ainda o uso do alcatrão para acelerar o processo de secagem da madeira verde.

Guimarães Neto (2005) apresentou estudo de um tipo específico de forno dos pontos de vista técnico e econômico. A avaliação da carbonização envolve uma análise da taxa média de aquecimento, da temperatura média do forno e do tempo de carbonização. Esse autor apresentou também uma análise química do carvão vegetal produzido e um indicador econômico e financeiro das melhorias na produção.

Assis (2007) apresentou um estudo para testar, avaliar e ajustar um sistema alternativo de carbonização da madeira em escala-piloto, incluindo a construção e teste de um protótipo. Seis sensores foram instalados para verificar o perfil térmico no interior do forno. Um método estatístico, baseado em regressão, foi utilizado para estudar a relação entre a temperatura média interna do sistema e a temperatura média dos gases eliminados pela chaminé. Com base na temperatura, três modelos foram ajustados: linear, cúbico e logarítmico. A partir dos resultados, esse autor identificou que o tempo de resfriamento do carvão pode ser reduzido.

De acordo com Gomes e Oliveira (1980), a madeira verde, quando submetida ao calor, em temperaturas elevadas, sofre uma série de transformações em que todos os seus componentes são exaustivamente modificados. Trugilho e Silva (1998) afirmaram que a carbonização da madeira é um fenômeno complexo e que gera elevado número de subprodutos. Um ciclo de produção de carvão vegetal é dividido em quatro fases, de acordo com a temperatura. Segundo Medeiros e Resende (1983) e Oliveira et al. (1982), abaixo de 200 ${ }^{\circ} \mathrm{C}$ ocorre a secagem da madeira verde. De $200{ }^{\circ} \mathrm{C}$ a $280^{\circ} \mathrm{C}$ ocorrem reações endotérmicas que proporcionam a liberação de ácido acético, metanol, água, $\mathrm{CO}_{2}$, entre outros. Entre $280^{\circ} \mathrm{C} \mathrm{e} 500^{\circ} \mathrm{C}$ surgem reações exotérmicas que liberam gases combustíveis como $\mathrm{CO}$ e $\mathrm{CH}_{4}$, além de alcatrão. Acima de $500{ }^{\circ} \mathrm{C}$ ocorre à liberação de pequenas quantidades de substâncias voláteis, em especial $\mathrm{H}_{2}$.

Em todos os artigos apresentados anteriormente, verificou-se que a análise térmica do processo de produção de carvão vegetal é essencial e que a qualidade 
do produto final está ligada diretamente às temperaturas envolvidas. Tais fatos justificam a instrumentação térmica dos fornos e o desenvolvimento do sistema eletrônico proposto neste trabalho.

\section{MATERIAL E MÉTODOS}

O objetivo deste trabalho foi instrumentar e monitorar a temperatura em fornos destinados à produção de carvão vegetal. Nesse sentido, a Figura 1 mostra o desenho de um forno típico, construído com tijolos de alvenaria e com geometria retangular. O forno é denominado $\mathrm{RAC} 220(\mathrm{R}=$ retangular, $\mathrm{AC}=$ acesita, $220 \mathrm{~m}^{3}$ de capacidade de madeira enfornada), com dimensões de $25 \mathrm{~m} \mathrm{x} 4 \mathrm{~m}$ x $4 \mathrm{~m}$ (comprimento x largura $\mathrm{x}$ altura). $\mathrm{O}$ forno possui em suas extremidades portas de aço, revestidas com material refratário.

A instrumentação consiste na instalação de 22 sensores do tipo PT100 em cada forno, divididos em quatro zonas distintas do forno, ou seja, cinco sensores na zona 1 próxima à porta esquerda do forno, 10 sensores nas zonas 2 e 3 próximas ao centro do forno, cinco sensores na zona 4 próxima à porta direita e um sensor em cada chaminé. A Figura 1 mostra o esquema do processo de instrumentação de um forno.

Os sensores são conectados a uma placa-mãe que emite o sinal a um computador por meio de um circuito eletrônico e de uma rede sem fio. As temperaturas serão armazenadas em um software que retorna os dados medidos na forma de mapas térmicos, gráficos e tabelas.

A Figura 2 apresenta a instrumentação térmica, a instalação dos equipamentos, o sistema de comunicação entre os fornos e a central de monitoramento denominada servidor.

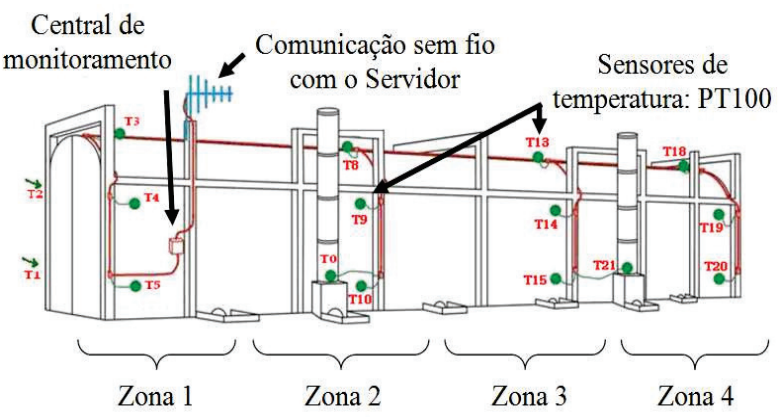

Figura 1 - Instrumentação térmica de um forno. Figure 1 - Thermal instrumentation of a kiln.
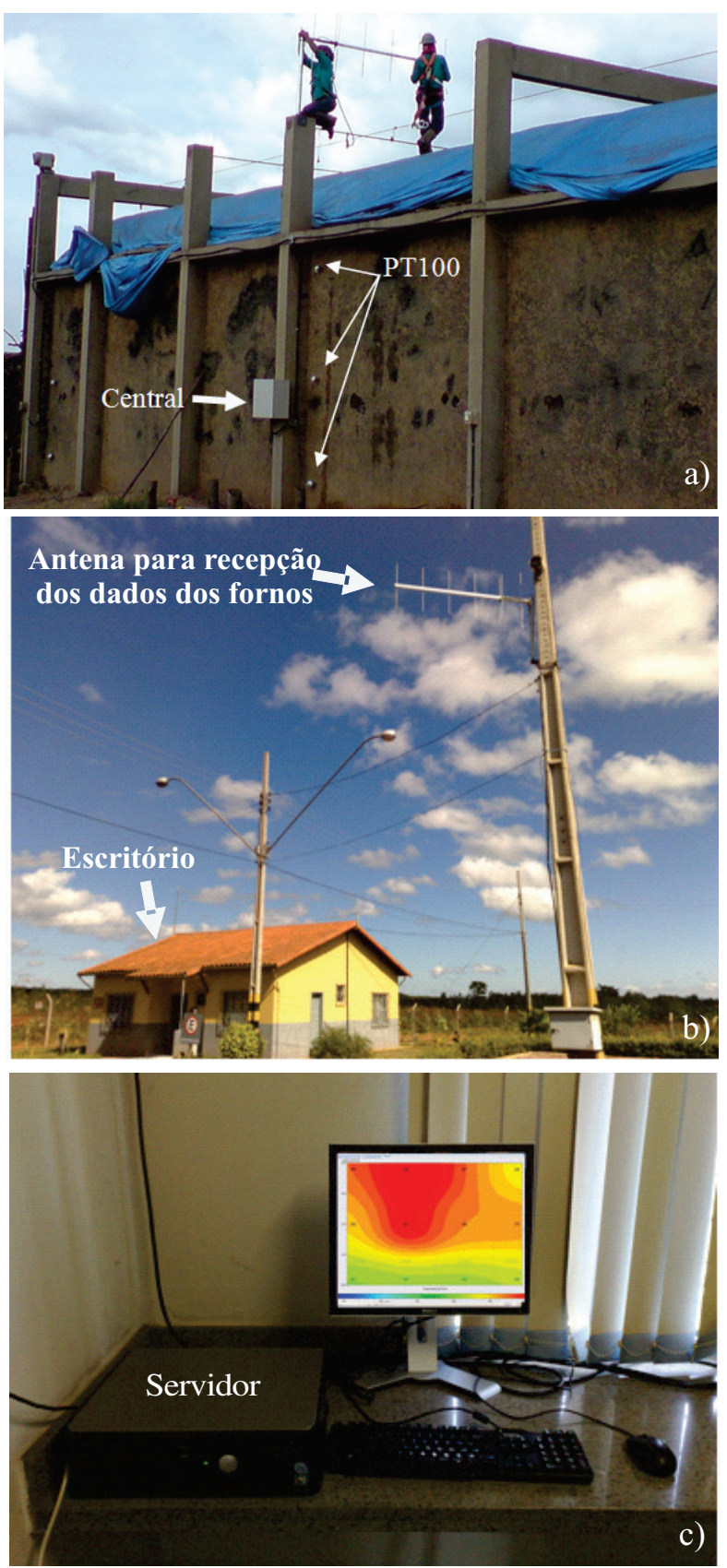

Figura 2 - Instalação dos equipamentos no forno RAC220: a) Montagem da antena para envio de dados; b) Escritório central para recepção dos dados; e c) Computador com software gráfico para análise dos perfis térmicos nos fornos.

Figure 2-Equipments installed in a RAC220: a) Aerial set in a kiln for wireless communication; $b$ ) Central office; and c) Computer with graphical software to analyze the thermal profiles inside a kiln.

Revista Árvore, Viçosa-MG, v.36, n.4, p.787-796, 2012 
O sistema inclui envio de dados via rádio (até $3 \mathrm{~km}$ ), e o hardware de monitoramento é equipado com um carregador e bateria auxiliar que proporciona 14 dias de medições ininterruptas na ausência de energia elétrica. Nesse caso, as temperaturas são armazenadas em um pendrive instalado no próprio hardware. No servidor, um software é responsável por apresentar os dados na forma de mapas térmicos, gráficos e tabelas que são atualizados em tempo real, automaticamente a cada $5 \mathrm{~min}$.

A concepção dos equipamentos e do sistema eletrônico, relacionados a outros já existentes no mercado de automação e controle, baseou-se nas seguintes exigências:

- Custos reduzidos com relação a outros sistemas industriais.

- Facilidade da instalação.

- Desenvolvimento de tecnologia própria para parcerias futuras.

- Possibilidade de atualização e incorporação de novas funções e componentes.

A partir de pesquisa relacionada aos sistemas industriais já existentes e outros desenvolvidos por instituições de ensino, verificou-se que a compra de todos os equipamentos de medição e acessórios aumentaria muito o custo final do projeto. Nesse sentido, apenas alguns componentes do sistema foram comprados, como sensores térmicos (PT100), cabos e componentes eletrônicos. Em contrapartida, os hardwares e softwares foram desenvolvidos na Faculdade de Engenharia Mecânica da Universidade Federal de Uberlândia (UFU).

Para medição da temperatura, foi realizado um estudo prévio acerca de sensores disponíveis no mercado capazes de medir temperaturas superiores a $500{ }^{\circ} \mathrm{C}$. Tais sensores devem ainda resistir às intempéries e resíduos gerados durante a produção de carvão vegetal. Assim, verificou-se que os sensores denominados Resistance Temperature Detectors (RTD) seriam os mais adequados ao processo de produção de carvão vegetal. A Figura 3 apresenta um sensor RTD típico e aplicações práticas deste. Por meio dessa figura, verifica-se que os sensores têm que resistir às condições práticas de trabalho e às intempéries. A Figura 3b apresenta um sensor instalado no forno.
Durante o ciclo de carbonização, é comum encontrar alcatrão em cima dos sensores, em especial naqueles próximos às chaminés. A Figura $3 \mathrm{c}$ mostra que o PT100 deve ser lacrado para evitar a entrada da poeira e água da chuva. Nota-se ainda, nessa figura, o circuito eletrônico posicionado dentro do sensor e que foi desenvolvido pelo grupo de pesquisa da Faculdade de Engenharia Mecânica da UFU. Neste trabalho, os sensores e o sistema eletrônico foram calibrados previamente usando uma célula quente para uma escala da temperatura entre $30{ }^{\circ} \mathrm{C}$ e $500^{\circ} \mathrm{C}$, apresentando perfil linear.

Para controlar a comunicação entre os sensores, enviar os dados adquiridos ao servidor e armazenálos, desenvolveu-se uma central de controle. Tal circuito tem como base um microcontrolador, responsável por quase todas as funções executadas pela central, com exceção da gravação dos dados. Para o controle dos fornos, os valores de temperatura medidos devem estar disponíveis aos operadores sob a forma de gráficos e tabelas, em tempo real de produção. Assim, os valores obtidos nos fornos são enviados a um servidor, que permite que eles sejam acessados por usuários cadastrados dentro ou fora da unidade de produção de carvão.

O circuito da placa-mãe conta também com um sistema de armazenamento local de dados, no caso um pendrive. Ele foi escolhido tendo em vista seu baixo custo e mobilidade de acesso aos dados no caso de falhas no sistema de comunicação sem fio. Ressaltase que a central pode operar tanto em modo online, enviando os dados em tempo real ao servidor, quanto offline, caso ocorra algum erro de comunicação com o servidor ou falta de energia elétrica. Nesse caso, a mudança entre os modos é realizada automaticamente pelo sistema. O sistema de armazenamento grava a data e hora de cada amostragem.

O sistema contempla ainda um circuito responsável pela detecção de queda de energia e outro para medir o nível de carga nas baterias. As falhas quando detectadas são gravadas no pendrive e disponibilizadas no banco de dados quando o sistema retoma suas condições normais de trabalho. A presença de um no-break no sistema é indispensável, pois o processo de produção de carvão vegetal independe de energia elétrica e, portanto, na ausência dessa energia o sistema deve continuar monitorando as temperaturas no interior dos fornos e as disponibilizando aos carbonizadores. 


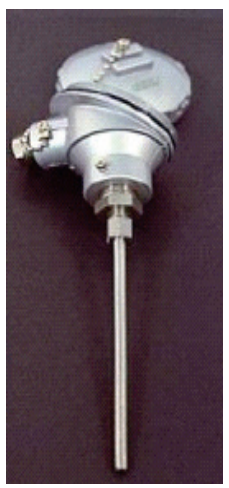

a)

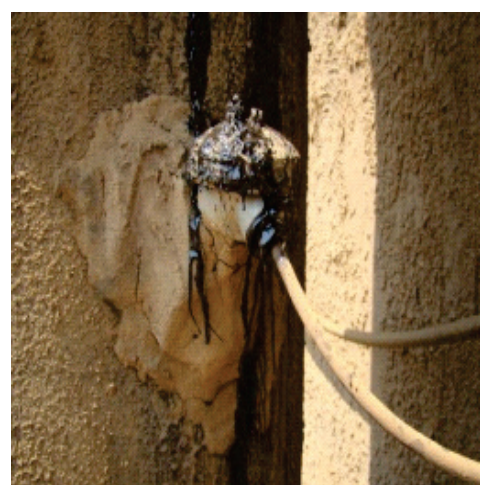

b)

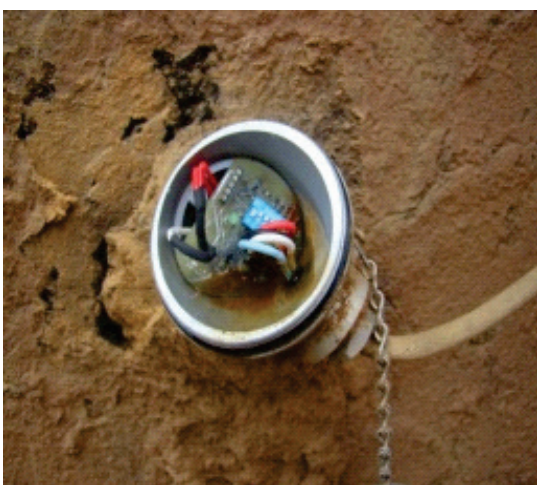

c)

Figura 3 - PT100 a) PT100 típico; b) Sensor instalado; e c) Sensor submetido às intempéries. Figure 3-PT100 a) Typical PT100; b) Sensor installed; and c) Sensor submitted to weather.

Para que os carbonizadores tenham acesso aos dados adquiridos nos fornos, um computador (servidor) foi instalado no escritório da unidade. Além de permitir a visualização gráfica, o servidor armazena os dados de temperatura dos ciclos térmicos e solicita dados da produção, por exemplo tipo de madeira enfornada, diâmetro médio das toras, peso da madeira, peso e qualidade do carvão produzido e falhas visuais identificadas durante a produção.

O servidor gerencia ainda a comunicação $W E B$, sincronismo das leituras dos fornos e realiza uma análise prévia dos valores de temperatura medidos, além de ter outras funcionalidades. Ele possui um receptor sem fio, responsável pela comunicação com os fornos. O receptor foi separado em duas partes, uma responsável pela recepção propriamente dita e outra pela comunicação com o computador. Ressalta-se que a distância entre o servidor e os fornos varia de 300 $\mathrm{m}$, para o forno mais próximo, e $2 \mathrm{~km}$ para o forno mais distante.

No servidor são instalados diversos softwares, cada um com a sua devida função: comunicação sem fio, administração de banco de dados, visualização gráfica e análise estatística da produção. Nesse caso, o software e alguns aplicativos apresentados anteriormente devem funcionar continuamente, pois são responsáveis pelo envio e recepção de dados entre o servidor e os fornos. Cópias de segurança dos dados são arquivadas em determinados períodos de tempo, para garantir a integridade dos dados e assegurar que, em caso de perda total do servidor, eles possam ser recuperados.
Informações detalhadas a respeito dos circuitos eletrônicos serão omitidas em razão do contrato de sigilo firmado entre a empresa colaboradora e a FEMECUFU (Mulina, 2011).

É importante destacar que, por meio de análise dos custos relativos à concepção e montagem do protótipo apresentado neste trabalho, estima-se que a implantação total do sistema seja em torno de US $\$ 15.000,00$ para um forno. Nesse caso, o projeto contempla a montagem do hardware e 22 sensores em um forno, além da instalação de um monitor e computador adaptado com os hardwares e softwares personalizados. É importante ressaltar que um sistema de capacidade similar, disponível no mercado de automação e controle, teria custo inicial de US\$25.000,00. Nesse caso não foram contabilizados os custos com a montagem e instalação do sistema comercial. A expansão e montagem do sistema proposto neste trabalho estão estimadas em US\$7.000,00 para cada forno adicional.

Na sequência, apresenta-se uma aplicação da instrumentação térmica no processo de produção de carvão vegetal.

\section{RESULTADOS}

Durante a etapa de testes do sistema de monitoramento, realizou-se um ciclo de carbonização diferenciado, no qual foram adotadas algumas intervenções no forno baseadas na avaliação dos campos térmicos desenvolvidos durante a produção de carvão vegetal. Nesse sentido, a Figura 4 apresenta as temperaturas internas do forno, conforme as zonas térmicas definidas na Figura $1 \mathrm{~b}$.

Revista Árvore, Viçosa-MG, v.36, n.4, p.787-796, 2012 

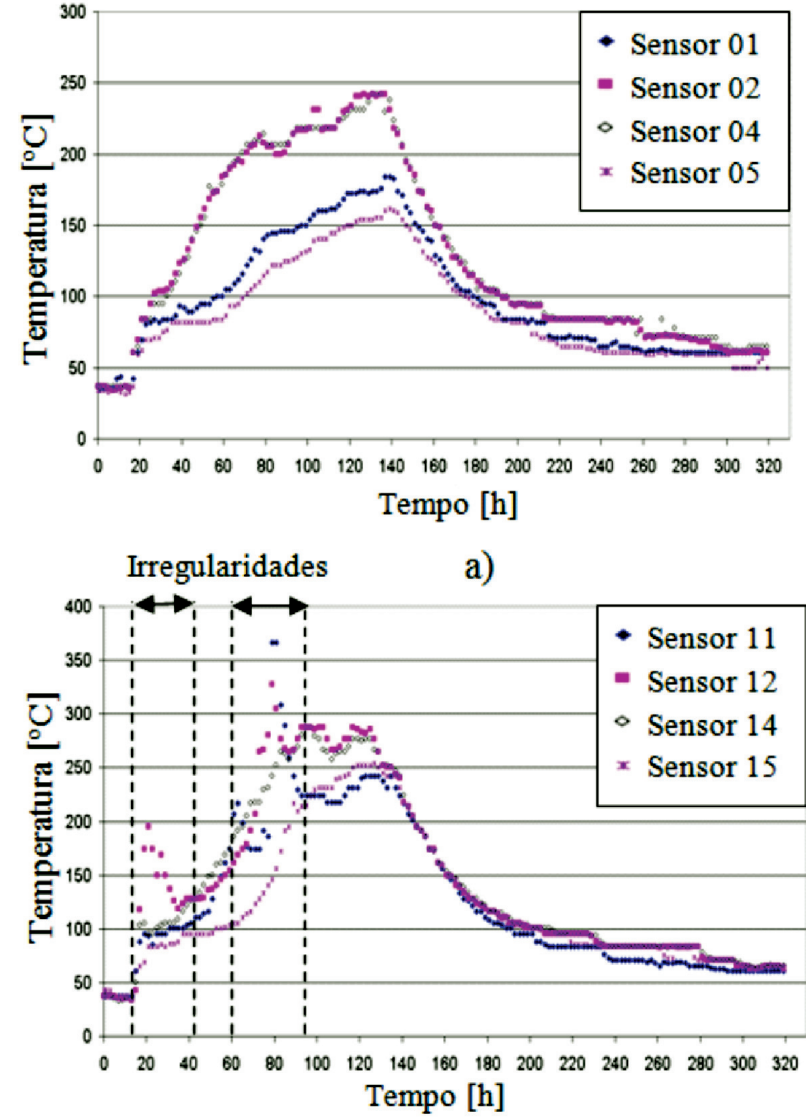

c)

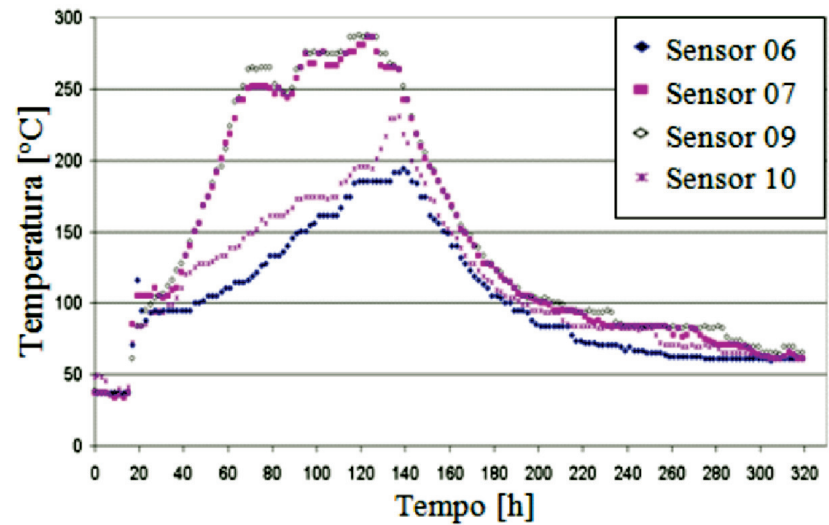

b)

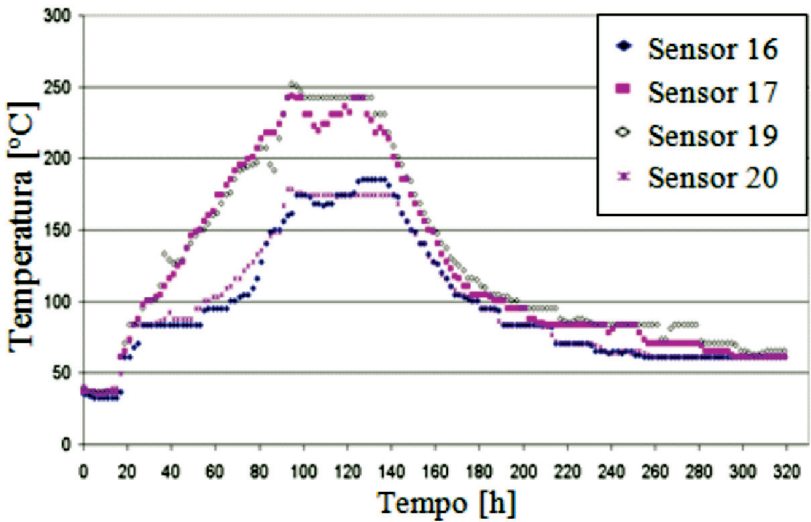

d)

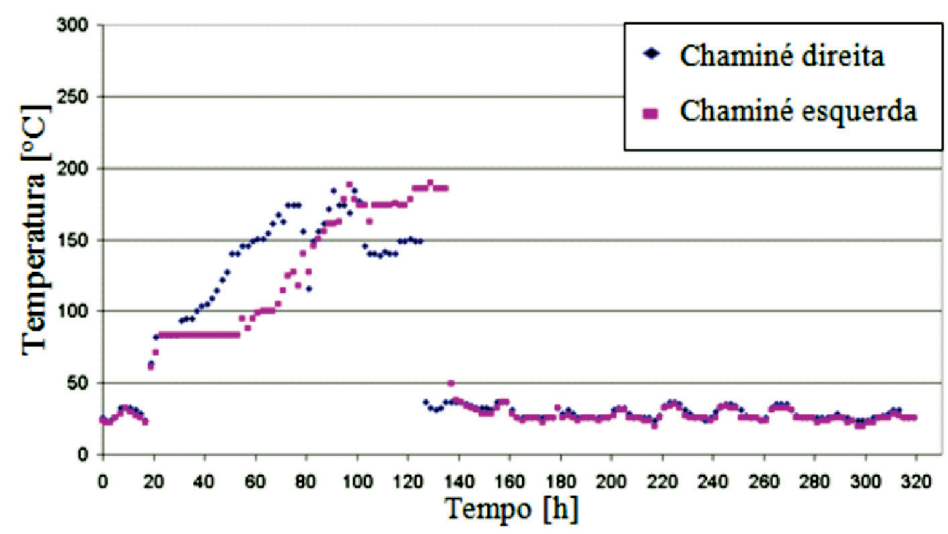

e)

Figura 4 - Temperaturas no forno: a) Temperaturas da zona 1 do forno próxima à porta esquerda; b) Temperaturas da zona 2 próxima ao centro do forno; c) Temperaturas da zona 3 próxima ao centro do forno; d) Temperaturas da zona 4 do forno próxima à porta direita; e) Temperaturas monitoradas nas chaminés.

Figure 4-Temperatures inside the kiln: a) Zone 1 near to the left door; b) Zone 2 near to center of the kiln; c): Zone 3 near to center of the kiln; d) Zone 4 near to the right door; and e) Temperatures inside the chimneys.

Revista Árvore, Viçosa-MG, v.36, n.4, p.787-796, 2012 


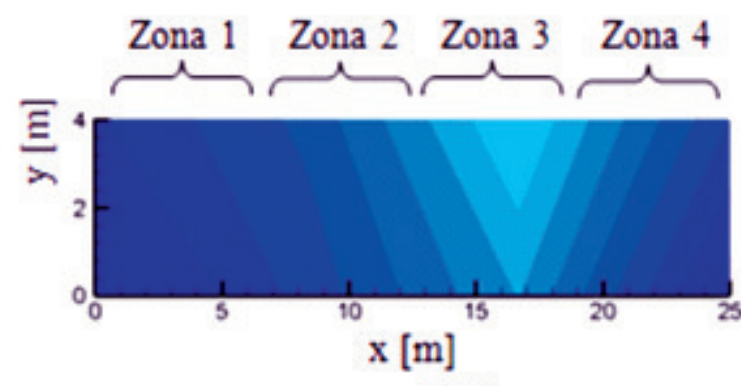

a) 15 horas

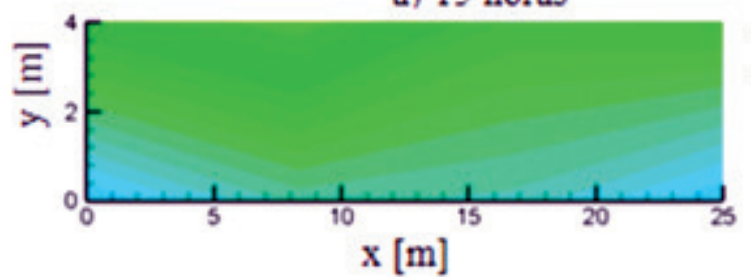

c) 32 horas

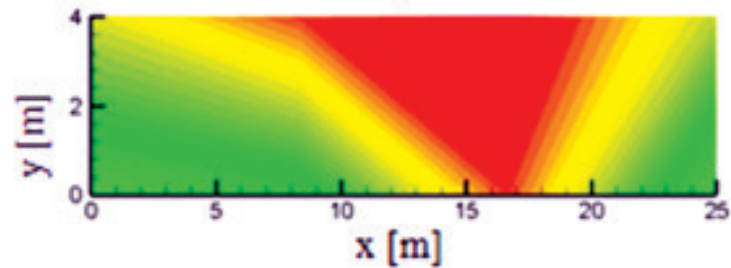

e) 80 horas

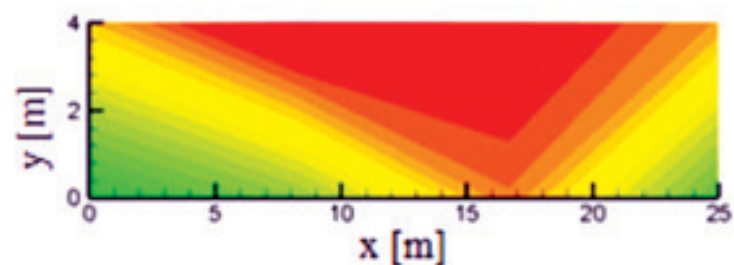

g) 125 horas

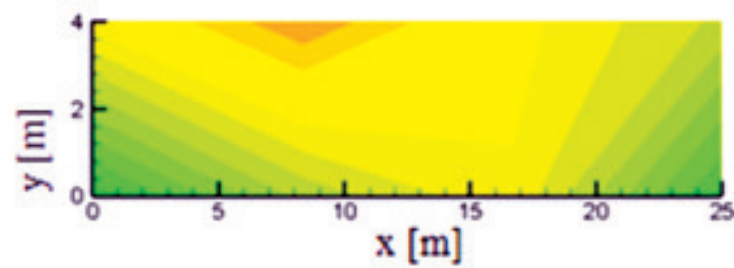

i) 150 horas

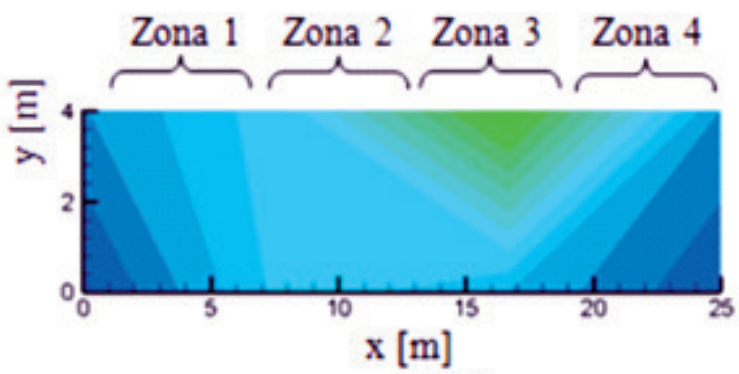

b) 20 horas

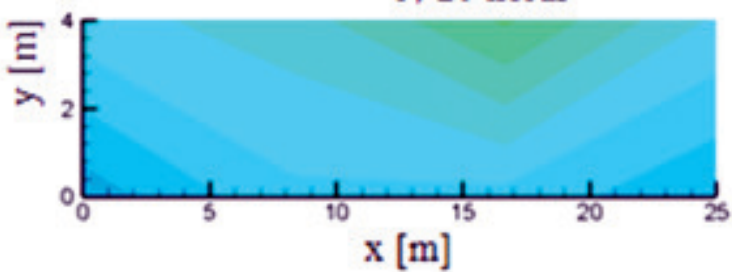

d) 65 horas

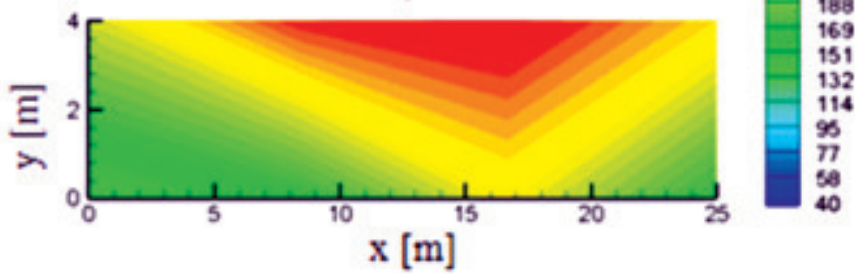

f) 106 horas

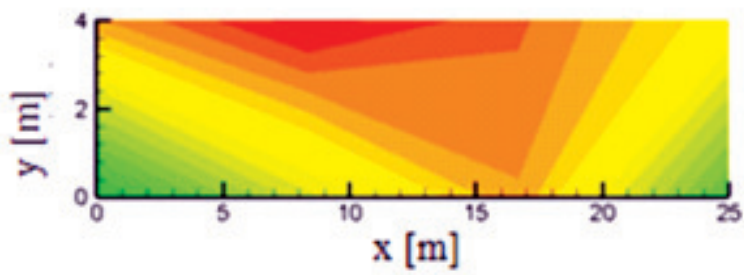

h) 135 horas

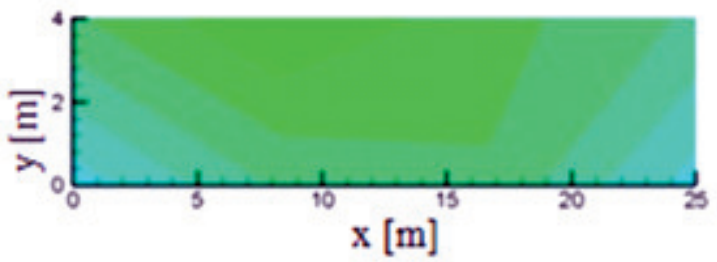

j) 170 horas

Figura 5 - Evolução dos campos térmicos no interior do forno RAC220: 15 h: secagem - pirólise; b) 20 h: secagem - pirólise; c) 32 h: pirólise; d) 65 h: pirólise; e) 80 h: pirólise; f) 106 h: pirólise; g) 125 h: chaminé direita fechada; h) $135 \mathrm{~h}$ : chaminé esquerda fechada; i) $150 \mathrm{~h}$ : resfriamento; e j) $170 \mathrm{~h}$ : resfriamento.

Figure 5 - Thermal fields inside the kiln: a) 15 hours: drying - pyrolysis; b) 20 hours: drying - pyrolysis; c) 32 hours: pyrolysis; d) 65 hours: pyrolysis; e) 80 hours: pyrolysis; f) 106 hours: pyrolysis; g) 125 hours: chimney on the right was closed; h) 135 hours: chimney on the left was closed; i) 150 hours: cooling; and j) 170 hours: cooling. 
O sistema de monitoramento permite ainda uma análise térmica transiente do ciclo de produção, conforme apresentado na Figura 5. Nesse caso, o carbonizador pode visualizar o perfil térmico no interior do forno em tempo real, solicitar ao programa animação gráfica representativa da evolução da temperatura ou, ainda, analisar ciclos de produção já finalizados.

Na sequência são apresentadas discussões a cerca dos resultados obtidos a partir da instrumentação e monitoramento térmico de um forno de alvenaria RAC220.

\section{DISCUSSÕES}

A Figura 4a apresenta as temperaturas medidas na zona 1 , próxima à porta esquerda do forno, na qual se observa claramente uma diferença entre as temperaturas medidas na região superior do forno ( 2 e 4) e a base (região inferior: sensores 1 e 5). Nesse caso, durante a pirólise a diferença de temperatura entre os sensores do topo e da base chega a $50{ }^{\circ} \mathrm{C}$. No entanto, durante o processo de resfriamento (após 140 h de produção) as temperaturas tendem a se igualar rapidamente.

A Figura $4 \mathrm{~b}$ apresenta as temperaturas na zona 2 do forno, composta pelos termopares 6,7,9e 10. Verifica-se, nessa figura, que as temperaturas nessa região são maiores do que aquelas apresentadas próximas à porta esquerda. As temperaturas no topo do forno alcançam $280^{\circ} \mathrm{C}$ e há diferença de aproximadamente $100{ }^{\circ} \mathrm{C}$ entre o topo e a base do forno. Segundo a literatura, a temperatura adequada para a produção de carvão é entre $280^{\circ} \mathrm{C}$ e $300{ }^{\circ} \mathrm{C}$. Um forno com temperatura abaixo de $250^{\circ} \mathrm{C}$ pode apresentar grandes quantidades de tiços (madeira que não se transformou em carvão). Assim, conforme os perfis térmicos identificados na Figura $4 \mathrm{ab}$, verificou-se que há grande probabilidade da formação de tiços na base e na região próxima à porta esquerda do forno.

Durante todo o período de produção, a zona 3 foi a única a apresentar irregularidades em relação às demais zonas térmicas. A Figura 4c mostra picos de temperatura durante determinados períodos do ciclo de produção. Nesse caso, as irregularidades foram detectadas por meio dos sensores 11 e 12. Assim, no momento da primeira falha, após $20 \mathrm{~h}$ do início do processo de produção foi solicitado a um carbonizador que fosse até o forno e fizesse uma análise visual para constatar se havia alguma irregularidade na região térmica definida como zona 3. Nesse caso, foram visualizadas rachaduras na parede doforno de alvenaria, oqueé muito comum durante o processo de aquecimento e resfriamento, ou seja, expansão e contração dos gases no interior do forno. As rachaduras, por sua vez, tornam-se inconvenientes no processo de produção, pois permitem que o ar entre no interior do forno gerando focos de incêndio. Tal falha é corrigida fazendo o "barrelamento" da parede externa do forno, ou seja, um caminhão- pipa jorra lama nas paredes para auxiliar na vedação. Ressalta-se que a lama é oriunda do mesmo tipo de argila aplicada na construção do forno. Nesse caso, mesmo corrigindoo problema, outra falha voltou a ocorrer. Novamente, os técnicos foram até o forno, identificaram novas rachaduras e tiveram que repetiro processo de "barrelamento" para corrigir rapidamente o problema.

Tais problemas mostram que as temperaturas internas do forno devem ser monitoradas e controladas durante todo o processo de produção, pois os ciclos de produção são demasiadamente longos e suscetíveis a falhas. Além disso, nos gráficos, nota-se grande diferença entre a temperatura da base e a do topo do forno, o que não é adequado para o processo de produção de carvão vegetal. O correto seria uma temperatura homogênea, para garantir a produção de carvão vegetal em todas as zonas do forno e diminuir a formação de tiços e cinzas.

A Figura 4d, por sua vez, apresenta as temperaturas da zona 4, localizada próxima à porta direita do forno, onde se encontram os sensores 16, 17, 19 e 20. Como previsto, os sensores 17 e 19, situados no topo do forno, apresentam temperaturas mais altas do que as medidas pelos sensores 16 e 20, situados na base. Além disso, as temperaturas são semelhantes àquelas identificas próximas à porta esquerda e menores do que as apresentadas na região central do forno. Tal fato confirma as zonas 1 e 4 como as mais frias do forno. Tal fato é justificado devido ao uso de portas metálicas, o que contribui para maior dissipação do calor e, consequentemente, a formação de tiço.

As temperaturas monitoradas nas chaminés são apresentadas na Figura 4e. Nesse caso, torna-se possível identificar claramente a transição da fase de pirólise (20 h até $130 \mathrm{~h}$ ) para a fase de resfriamento (depois de 130 h). Nessa figura, verifica-se uma diferença de $10 \mathrm{~h}$ entre o fechamento das chaminés, e a primeira 
a ser fechada se localiza próxima à zona 3, onde as temperaturas mais altas foram identificadas. Tal procedimento foi executado com base na experiência do carbonizador, no intuito de transferir a energia excedente da zona 3 para as demais e, assim, tentar homogeneizar a carbonização da madeira. Ressalta-se que a prática-padrão adotada pelos carbonizadores foi inserida no banco de dados do software. Por meio dessa iniciativa, o software poderá no futuro informar possíveis ações a serem seguidas conforme a falha identificada no processo.

Outra vantagem do sistema de monitoramento consiste na análise térmica transiente do ciclo de produção. A Figura 5 apresenta os resultados do ciclo descrito anteriormente. Nesse caso, o eixo das abscissas (x) corresponde ao comprimento do forno, ou seja, $0 \mathrm{~m} \leq$ $\mathrm{x} \leq 25 \mathrm{~m}$, sendo definido como o comprimento desde a porta esquerda até a porta direita do forno. O eixo das ordenadas (y) representa a altura do forno, ou seja, $4 \mathrm{~m}$. Assim, por meio das temperaturas medidas em pontos específicos, modelos térmicos e softwares gráficos, tem-se o perfil térmico transiente no interior do forno, conforme as zonas definidas previamente. Informações detalhadas a respeito de outros ciclos de carbonização estão disponíveis no trabalho de Oliveira (2009).

Na Figura 5, verifica-se claramente que os picos de temperatura identificados na zona 3 , após $20 \mathrm{~h}$ de ciclo (Figuras 4ce-g), tiveram grande influência na carbonização, pois o perfil de temperatura se tornou totalmente irregular. Analisando a Figura 5hj, verifica-se que a simetria térmica entre as zonas 1 e 4 (próximas às portas) e 2 e 3 (próximas às chaminés) só foi recuperada após 170 h de ciclo, na fase de resfriamento do forno. Tais fatos comprovam e justificam aplicar a instrumentação térmica ao processo de produção de carvão vegetal.

\section{CONCLUSÕES}

Este trabalho apresentou uma proposta de instrumentação térmica para fornos destinados à produção de carvão vegetal. O objetivo consiste em medir a temperatura a partir de sensores localizados em vários pontos dentro do forno e estabelecer relação entre temperatura e produção de carvão. Nesse sentido, um sistema eletrônico foi desenvolvido para analisar e otimizar a produção, além de aumentar a eficiência térmica dos fornos. Esse sistema pode ainda auxiliar na melhoraria da carbonização da madeira com consequente aumento da qualidade e produtividade de carvão. De acordo com os resultados, verifica-se que a instrumentação térmica deve ser utilizada para aprimorar e corrigir o ciclo de carbonização, a fim de aumentar a produtividade e diminuir os custos. Tal fato foi comprovado no estudo de caso, em que os perfis térmicos auxiliaram os carbonizadores na identificação de irregularidades no processo e a corrigi-las em tempo real de produção.

\section{AGRADECIMENTOS}

À parceria com a Votorantim Siderurgia Unidade Florestal e com as agências de fomento (CNPq, FAPEMIG e CAPES), pelo apoio.

\section{REFERÊNCIAS}

ASSIS, C. O. Sistema alternativo para carbonização de madeira. 2007. 49f, Dissertação (Mestrado em Engenharia Florestal) Universidade Federal de Lavras, Lavras, 2007.

GUIMARÃES NETO, R. M. Avaliação econômica e financeira de projetos de fornos dos tipos container industrial e retangular de 40 estéreos. Revista Árvore, v.31, n.4, p.709-715, 2007.

GOMES, P. A.; OLIVEIRA, J. B. Teoria da carbonização da madeira. In: PENEDO, W. R. (Ed.) Uso da madeira para fins energéticos. Belo Horizonte: CETEC, 1982. p.27-41.

MEDEIROS, C. A.; RESENDE, M. E. A. Alcatrão vegetal: perspectivas de produção e utilização. Revista da Fundação João Pinheiro, v.13, n.9-12, p.42-48, 1983.

MUlina, B. H. O. Desenvolvimento de um sistema eletrônico para monitoramento térmico de fornos industriais. 2011. 88f, Dissertação (Mestrado em Engenharia Mecânica) - Universidade Federal de Uberlândia, Uberlândia, MG, 2011.

OLIVEIRA, R. L. M.Instrumentação e análise térmica do processo de produção de carvão vegetal. 2009. 100f, Dissertação (Mestrado em Engenharia Mecânica) - Universidade Federal de Uberlândia, Uberlândia, MG, 2009

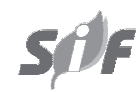

Revista Árvore, Viçosa-MG, v.36, n.4, p.787-796, 2012 
OLIVIERA, J. B.; GOMES, P. A.;

ALAMEIDA, M. R. Caracterização do processo de fabricação de carvão em fornos de alvenaria. In: PENEDO, W. R.

(Ed.) Carvão vegetal: destilação, carvoejamento, propriedades, controle de qualidade. Belo Horizonte: CETEC, 1982. p.63-102, 1982 .
RAAD, T. J.; WINTER, M. Pesquisa e desenvolvimento na produção de carvão vegetal. Local: V\&M Florestal, 2007.

TRUGILHO, P. F.; SILVA, D. A. Influência da temperatura final de carbonização nas características físicas e químicas do carvão vegetal de jatobá. Revista Árvore, v.21, n.1, p.113-130, 1997. 